\title{
Mobility and health sector development in China and India
}

\author{
Jennifer Holdaway ${ }^{a,}{ }^{*}$, Peggy Levitt ${ }^{\text {b, c }}$, Jing Fang ${ }^{d}$, Narasimhan Rajaram ${ }^{e}$ \\ a Social Science Research Council, USA \\ ${ }^{\mathrm{b}}$ Wellesley College, USA \\ ${ }^{\mathrm{c}}$ Harvard University, USA \\ ${ }^{\mathrm{d}}$ Kunming Medical University, PR China \\ e Central University of Gujarat, India
}

\section{A R T I C L E I N F O}

\section{Article history:}

Available online 13 February 2015

\section{Keywords:}

China

India

Mobility

Health

Development

Knowledge transfer

\begin{abstract}
A B S T R A C T
China and India are both attempting to create comprehensive healthcare systems in the context of rapid but uneven economic growth and rapidly changing burdens of disease. While in each country the referencing of international policies and work experience abroad have been part of this process, research has yet to examine the kind of knowledge that is exchanged or the various actors involved in knowledge circulation. Based on a study of two sub-national contexts, this article focuses on the role Chinese and Indian health professionals who have studied and worked overseas play in introducing ideas and practices about healthcare provision and health education. We found that experience abroad influenced individuals, institutions, and each society differently and with some contradictory effects. International experience clearly contributed to personal growth and led individuals to support the adoption of new institutional practices, such as more egalitarian relations between doctors and patients and between students and teachers. However, the content of what individuals learned overseas and the mechanisms through which this knowledge was introduced back into homeland settings often reinforced rather than ameliorated institutional hierarchies and social inequalities. While the scope of this research was limited, we suggest that more explicit analysis of the role professional migrants play in transferring ideas and practices within the health sector would be valuable for policymakers and funders seeking to support a more productive interaction between local and global knowledge.
\end{abstract}

() 2015 Elsevier Ltd. All rights reserved.

\section{Introduction: policy learning, migration and development}

China and India are both seeking to expand and improve the provision of healthcare services and develop their medical schools and other training facilities for healthcare personnel. In each country, the referencing of international policies and practices has been part of this effort and many health professionals have gone abroad to participate in a range of training and exchange programs. Here we present the findings of a qualitative study in two subnational contexts that examined how the overseas experiences of health professionals from China and India are influencing health system development and health education in their places of origin.

The issues we explore lie at the intersection between the

\footnotetext{
* Corresponding author. Social Science Research Council, Institute of Geographic Sciences and Natural Resources Research, 11A Datun Road, Room 3701, Beijing 100101, PR China.

E-mail address: holdaway@ssrc.org (J. Holdaway).
}

literature on global policy and knowledge transfers and work in migration studies on the circulation of ideas and practices through transnational networks. The question of how learning about policy and institutional and individual capacity development takes place across national contexts has been addressed from a number of disciplinary perspectives. Initially, this research was conducted primarily by political scientists and sociologists and considered the ways in which national governments draw on international experience to develop their own strategies and initiatives. It broadened from an early focus on state actors to include the role of international organizations, NGOs, and consultants in policy transfers, and attempted to classify the different types of transferred knowledge, the conditions and motivations for transfer, the nature of learning, and the factors that shape successful adoption or failure (Bennett, 1991; Dolowitz and Marsh, 1996, 2000; Robertson, 1991; Rose, 1991).

More recently a new stream of work has developed, much of it by geographers and anthropologists, which takes a critical attitude towards earlier conceptualizations of straightforward "policy 
transfers." This work emphasizes the hybrid nature of what circulates through global knowledge networks, referring to "assemblages" of policy models and institutional forms as well as specific techniques and practices. It also stresses the ways in which ideas and practices mutate in the process of moving across space (for a discussion, see Peck, 2011). These researchers trace processes of "inter-referencing" that can involve vague forms of mutual influence including "citation, allusion, aspiration, comparison and competition" (Ong, 2011:17). Furthermore, where earlier studies on policy learning focused on flows of knowledge between industrialized nations or from richer to poorer countries (for example, Duan, 2010; Dawes et al., 2011), these studies explore the circulation of knowledge among countries and cities whose regional location or development pathways present similar challenges (for example Ong, 2011).

Although not explicitly linked, to the extent that they consider how societies seek to mobilize international knowledge to reform or enhance capacity in particular policy sectors, these debates intersect with research in development studies and international relations that focuses on capacity building. This work considers the challenges involved in attempts to import global norms, policies, institutional forms and mechanisms that are regarded as effective in improving the functionality of institutions or represent various types of "best practice." It has also become more critical over time, moving away from discussions of wholesale "transfer" or "borrowing" toward exploring the ways in which ideas and institutional forms mutate, interacting and melding with local knowledge and practices (Pritchett et al., 2012; Rodrik, 2008) to form "localized" (Acharay, 2004) or "vernacularized" (Levitt and Merry, 2009) versions. Many of these accounts acknowledge the difficulty of specifying exactly what such "capacity building" or "capacity strengthening" actually entails, but they recognize that it can and usually needs to take place on individual, institutional, and societal levels, and that it can involve a number of components ranging from the mastery of specific individual competencies and organizational reforms that improve overall functional capacity to shifts in perspective or attitude that are needed to change priorities or modes of work (Mark and Jones, 2013).

Despite the widespread use of the term "mobility" in much of this writing (Peck, 2011), research on how ideas, policies, practices, and capabilities circulate generally treats the actors involved as members of either "importing" or "exporting" places, overlooking the role of migrants and other mobile people. Even the growing literature on transnational knowledge networks tends to discuss participants as if they belong to distinct national groups. At the same time, if migrants seem to be absent from the policy learning literature, the questions it addresses are also largely missing from migration studies. Many scholars recognize that international migration can profoundly affect sending country development, and development planners and policymakers increasingly acknowledge the need to consider migration as a central cause and consequence of development (Castles and Delgado Wise, 2008; De Haas, 2008; Mazzucato, 2011). However, research on the contributions migrants make to their home countries has focused primarily on economic transfers, including remittances, investments in businesses, the transfer of technological or commercial skills and knowhow, and charitable donations.

A smaller but growing literature within migration studies considers the role that migrants play in transferring cultural and social norms, ideas and practices, and skills and know-how, now often referred to as "social remittances" (Levitt, 1998; Levitt and LambaNieves, 2011). Although there is some consideration of how these may affect change at the regional and national levels, most of this work focuses on how individual and collective social remittances affect individuals, households, and communities. To the extent that migration researchers have looked at political and policy change, it has mostly been in the context of migrants' participation in home country elections, in social movements, and in conflict situations (Eckstein and Najam, 2013; Lafleur, 2013). Kapur (2010) is unusual in considering the possible impact of returning elites on domestic economic policy and political inclusion in India.

Surprisingly, given the large number of individuals who go overseas for professional education, there has been very little research on the impact of skilled migration on particular policy areas. Knowledge circulation has been studied primarily in relation to commercial knowledge, technical skills (Saxenian, 2006), and academic knowledge production (for example, Jons, 2011, 2009). Work on the impact of migration on health policy and institutional development has focused largely on the causes, processes, and implications of the health worker "brain drain" from developing to developed countries (Okeke, 2013; Taylor et al., 2011; Sherr et al., 2012; Kangasniemi et al., 2007; Mullan, 2005).

But clearly, return migrants have historically played a highly visible role in shaping not only the overall development strategies of their countries of origin but also particular policy fields. Key Indian and Chinese political leaders, including Gandhi, Sun Yat-sen, and Deng Xiaoping, spent significant periods of time overseas and their experiences profoundly shaped their visions of development and leadership; other returnees had a strong influence on sectors ranging from health to the military. This pattern continues today, with large numbers of Chinese and Indians now going overseas for at least some part of their education or training and to gain professional experience. Upon return, many of these individuals assume roles in which they potentially exert considerable influence over institutional development and, in some instances, policy making. Some are involved in government-led processes of learning from international experience, but many more serve as informal conduits of information, norms, and behaviors.

Sending states are acutely aware of these dynamics, increasingly seeing migrants as an underutilized policy resource (Kapur and McHale, 2005; Levitt and Rajaram, 2013; Xiang, 2006). The Indian government created the official categories of NRI (Non-Resident Indian), PIO (People of Indian Origin) and OCI (Overseas Citizen of India) to encourage Indians abroad to maintain close homeland ties, and emigration policy has been an integral part of China's overall economic and social development strategy (Xiang, 2003). Since the process of economic reform and opening up began in the late 1970s, the Chinese government has encouraged skilled individuals to go overseas to study, directly sponsoring many of them. In the 1990s, policies were instituted to encourage return migration, including the establishment of special development zones and science parks in major cities and the provision of tax breaks and other incentives for returnees (Xiang, 2006). Increasingly, spending time overseas is a requirement for promotion in Chinese universities, and returnees are actively recruited to spur the development of new regional- and provincial-level universities (Luo et al., 2003).

China and India are also particularly promising cases for understanding the impact of migration on policy and institutional development because both countries are undergoing rapid economic and social transitions that generate new public health challenges, and require new policies, institutional forms, and mechanisms in response (Dummer and Cook, 2008). This fluid environment also provides opportunities for innovation not present in more settled contexts.

In particular, their size and rapid but uneven economic growth mean that in both countries there is considerable regional and local diversity in the demand for healthcare services and in the capacity to respond. Although life expectancy reached an average of 73 and 63.5 years by 2007, respectively (Dummer and Cook, 2008; The World Bank 2012), both China, and to a greater extent India, also 
continue to confront health problems associated with poverty. Lack of adequate nutrition, poor sanitation and hygiene, use of solid fuels for cooking and heating, and uneven access to healthcare services contribute to the persistence of respiratory, infectious, and bacterial diseases. Additionally, rates of malnutrition and maternal and infant mortality are high in certain regions, especially in the western provinces of China (Zhang et al., 2010) and in the poorest Indian states (Times of India, 2010). At the same time, non-communicable diseases usually associated with affluence are on the rise in urban and many rural areas as the result of more sedentary lifestyles, richer diets, smoking and excessive alcohol consumption (Gong et al., 2012; Marquez et al., 2011; Yang et al., 2013). Increasing rates of lung cancer, obesity, and diabetes threaten to undermine improvements in life expectancy in China (Marquez et al., 2011). In India, non-communicable diseases such as cardiovascular disease, cancer, and diabetes account for nearly half of all deaths.

In addition, industrialization and urbanization are bringing new problems associated with rapid growth in the absence of adequate regulatory capacity. These include the negative health impacts of air, water, and soil pollution from industry and high-input agriculture, as well as new infectious diseases and zoonoses associated with changing lifestyles and livestock-rearing activities (Holdaway, 2013). Studies have attributed additional deaths from respiratory disease to air pollution in China's cities, and at least part of the increase in cancer can be linked to pollution of various kinds (Yang et al., 2013; Yang and Zhuang, 2013). Although there have been fewer studies on the relationship between pollution and disease in India, it is likely that similar effects are occurring (Holdaway and Marshall, 2010). In both countries there are also significant gaps in the distribution of health facilities and professionals between rural and urban areas, and between affluent and poorer regions, although the disparities are larger in India (Dummer and Cook, 2008).

These different types of health problems require different kinds of disease surveillance, public health interventions, and health facilities and personnel. Many poverty-related illnesses are relatively straightforward in terms of causation and can often be prevented by investments in sanitation infrastructure and public health initiatives at the household or community level (Holdaway, 2013; Corvalán et al., 1999; Smith and Ezzati, 2005; Zhang et al., 2010). Treatment can be provided with relatively inexpensive equipment and drugs, and health workers do not necessarily require many years of training. As such, the major stumbling block to eradicating these kinds of diseases is not so much the availability of technology and highly skilled personnel, but the commitment of resources to improving the living and working environments of the poor and the provision of basic community health services. China's success in achieving quite comprehensive provision of basic healthcare in the pre-reform period is an illustration of this (Sen, 2011; Dummer and Cook, 2008). The health risks associated with rapid industrialization present much thornier problems and require a multifaceted governance response that includes not only the provision of health services, but also land use, environmental protection, and transportation policies to reduce pollution, as well as standards for occupational safety (Holdaway, 2013). Addressing lifestyle-related communicable diseases also entails policy initiatives that go far beyond the health sector to include urban planning, transportation, and the regulation of food, tobacco, and alcohol.

In terms of global knowledge and experience, there are many different types of health-related knowledge that would be relevant to the challenges China and India face. Clearly, national policies that affect the overall structuring and financing of health systems are of less relevance to the sub-national contexts we looked at, although these factors shape the larger context in which our respondents worked and some of the more senior among them participated in national-level debates about policy. However, broad understandings of the determinants of health at the individual, community, and societal levels are important because these will affect the ways in which medical professionals practice and teach as well as their priorities for research (Filc, 2004). The nature of the biomedical knowledge they acquire about specific disease causation and treatment or approaches to public health and disease prevention, as well as knowledge related to health management, institutional capacity building, and the training of health professionals, are also important.

We cannot attempt to identify and trace the flow of all these different types of knowledge systematically in this short article, but we want to highlight the fact that the relevance and usefulness of the experience of developed nations for China and India cannot be taken for granted. For example, biomedical understandings of the causes of disease have made significant contributions to effective diagnoses and the development of pharmacological and surgical treatments in developed countries, and in some cases direct transfers of specific policies or methods may be suitable. At the same time, the biomedical approach also has its limitations: most notably a dependence on ever-more sophisticated and expensive technologies, and a focus on curing rather than preventing disease, often in the context of the privatization of care (Filc, 2004; Parker et al., 2014, Levitt and Rajaram, 2013). Increasingly a consensus is emerging that to ensure effective disease prevention and health maintenance, and avoid the expense and suffering associated with the increase in chronic and non-communicable diseases, an integrated or "ecological" approach to health is needed that addresses its social and environmental determinants (Mannan et al., 2012; Beaglehole et al., 2011; WHO, 2008, 2005; Wilkinson and Marmot, 2003). However, although a "health in all policy" (WHO, 2008) and the importance of primary care (WHO, 1978) are accepted in principle, most countries have been unable to implement integrated approaches to health effectively.

Research on health sector development has raised other questions about the extent to which lessons from early industrializing countries can be applied to the developing world. Bloom and Standing (2008) challenge the assumption that models developed in Europe and the United States are appropriate for China and India, arguing that these systems are historical artifacts developed in response to particular circumstances, which are now under threat in the face of aging populations and rising medical costs. What appear to be "best practices" in those contexts may therefore be not only "un-implementable" in developing countries due to resource and capacity constraints, but also inappropriate. Instead, innovations that respond to local needs, resources, and pathways are required. Furthermore, periods of significant socioeconomic and demographic transition need approaches that are explicitly designed to be temporary and flexible in the face of change, and this also has implications for investments in institutional and human development. Husain (2012) found that in the implementation of China's New Rural Cooperative Medical System, a focus on best practices, identified as maximally efficient or cutting edge, has sometimes impeded the design of effective, low-cost mechanisms appropriate to (temporary) local circumstances.

\section{The national context: health systems in China and India}

In order to assess how the overseas experience of migrants relates to local needs, a brief introduction to the evolution of healthcare provision and related policies in China and India is helpful. Health systems in India and China have undergone significant changes over the last 30 years and continue to be in a state of flux. After 1949, the Chinese government invested in basic health institutions and services, with an emphasis on prevention, 
producing remarkably good health outcomes in relation to per capita GDP despite serious urban-rural and regional inequalities. Notably, this involved not only the provision of primary care services but also an emphasis on sanitation and investment in education in both rural and urban areas, including for women. This changed after economic reforms in the late 1970s dismantled the collective fiscal base for public healthcare, causing coverage to fall, costs to rise, and inequalities to increase. Deprived of funding, hospitals were obliged to raise revenues from the sale of drugs and medical procedures. By 1992 only 10\% of rural residents nationally had health insurance, compared with $90 \%$ in the 1970 s; preventive healthcare was discontinued, and lack of access to affordable healthcare became a major obstacle to poverty alleviation. In 2000 , the percentage of health costs paid out of pocket reached $60 \%$ (Alcorn and Bao, 2011). This led to pervasive concerns that getting healthcare was "hard and expensive" ("kanbing nan, kanbing gui").

In the last several years, healthcare reform has been continuously on the political agenda, and China has referenced the experience of the United States, Europe, and other countries, with researchers and government officials-some who have studied abroad-supporting different models. To a large extent, the debate hinges on the balance between government and market roles (Alcorn and Bao, 2011). The latest reform package, rolled out in 2010, has expanded insurance coverage, reducing rural-urban disparities and guaranteeing the availability of certain priority drugs (Freeman and Boynton, 2011). Despite fundamental changes in the organization and financing of healthcare over the last three decades, the state continues to play a much more important role in health care provision and the training of health professionals in China than it does in India, and the pendulum is swinging back towards an emphasis on improving primary care. China currently invests $2 \%$ of GDP in healthcare compared with $1.1 \%$ in India, and the percentage of health expenditures that come from the government is $45 \%$ compared with $26 \%$ (Sen, 2011).

India's health structure is founded on the Bhore Committee Report of 1946, which put public health workers on the government payroll and laid out a plan for a national public health system. However, in contrast to China, private sector providers were invited to participate in health care at all levels early on. Since 1990, with the opening up of the Indian economy, the private sector has grown even more rapidly than in China. However, private conventional medicine practitioners cluster in the wealthier cities. In rural areas, private practitioners are few, and mainly offer alternative forms of healthcare, including Ayurveda and homeopathy (Vital Statistics Division, 2012). At the same time, public rural health centers have found it increasingly difficult to retain or attract doctors and other health workers. The inequality of access to services is therefore more serious in India than in China. In 2012, the commission that develops India's Five-Year Plans identified healthcare as a key strategic challenge, concluding that "Good healthcare is perceived to be either unavailable or unaffordable" (Government of India, Planning Commission, 2012). There is also greater inequality in India than in China in terms of the principal social and environmental determinants of health, including access to sanitation as well as basic education, especially for poor rural women (WHO/ UNICEF, 2012). As of 2012, 646 million people in India still practiced open defecation, compared with only 16 million in China (WHO/ UNICEF, 2012). Female literacy rates in China in 2011 were over 91\%, compared with only 55\% in India (Lennard, 2012).

\section{Study sites and methods}

In order to avoid too strong a focus on national-level institutions that are uncharacteristically well endowed in terms of human and financial resources, we conducted our fieldwork in the provincial/ state capitals of Gujurat, in a province in Southwest China, and in the smaller cities and villages in those provinces. Focusing on this level of governance is particularly helpful in teasing out how the circulation of health-related knowledge and practices relates to the challenges of institutional and human development faced by poor areas undergoing rapid social change.

Southwest China shares borders with Myanmar, Laos, Vietnam, and Tibet. As a result, its population is one of the most diverse in China, with ethnic minorities making up more than a third of the population. Far from the nation's capital, in imperial times the region was a place of exile feared partly because of the prevalence of tropical diseases. Although still a relatively poor region that ranks at the bottom in terms of per capita GDP, the area's location now works to its advantage. It is a prime destination for tourists and retirees both for its mild climate and for the diverse scenery and cultures of its rural areas. It has a thriving tourist industry and produces many specialty agricultural products, although industry and mining are also increasingly important to its economy.

In terms of the burden of disease, Southwest China, like the rest of the country, has seen a shift from infectious diseases to noncommunicable diseases. After taking power in 1949, the Communist Party initially prioritized the control of plague, cholera, smallpox, malaria, and schistosomiasis, along with the introduction of basic medical and sanitation services (Lu et al., 2009). Although the burden of disease is now similar to the national average in terms of the balance between infectious and non-communicable diseases, life expectancy is still lower and the region's health problems continue to reflect its climate and geographical location. Endemic diseases like fluorosis and Kashin-Beck disease are still a problem in some parts of the province, while others are prone to higher rates of malaria and schistosomiasis. High rates of crossborder migration enable infectious diseases to enter from neighboring countries in which they are less well controlled and the active heroin trade means that some border areas also have high rates of HIV from intravenous drug use and subsequent transmission through sexual contact. As a result of these special circumstances, the region ranks high by national standards in incidence of plague, typhoid, and HIV/AIDS (Lu et al., 2009). Outcomes on maternal and child health are also relatively poor (Fang et al., 2010).

Gujarat falls in the middle of Indian states in terms of per capita GDP and state expenditures on health, and life expectancy is slightly higher than average at 65 for men and 64 for women. Deaths from diarrheal and many traditional communicable diseases are now quite rare, but tuberculosis is a serious problem, with 1480 deaths in 2010 (Vital Statistics Division, Commissionerate of Health, Medical Services, Medical Education and Research, Gandhinagar, Gujarat State, 2012), as is malaria. Meanwhile, lifestylerelated diseases are on the rise, and Gujurat has the tenthhighest obesity rate of 28 provinces (Government of India, Planning Commission, 2011, p. 68).

Our research team used a common list of questions to explore the ways in which international experience shapes the ideas and practices of individuals and the institutions in which they work. We focused on individuals working in medical universities and professional training institutions as well as medical service providers. First, we sought to understand why people migrated, their understandings of the relationship between health and development at that time, and the factors that led them to choose particular destinations and programs. A second group of questions focused on the content of their training abroad and teaching methods; the last set of questions asked about the ways in which people used or did not use the ideas and practices they learned overseas, their reintegration upon return, and continuing international collaboration more broadly. Research methods included individual interviews, 
small group discussions, and ethnographic methods (including attending classes and observing clinic and hospital environments). Information from fieldwork specifically for this project was supplemented by discussions with experts on the health sector in Beijing and Delhi, as well as by interactions with returned health professionals through other programs in which the investigators are involved. The project received an IRB exemption but respondents were ensured anonymity.

In each site we focused on a number of key institutions in order to understand how outside influences "converge" in different organizational settings to produce different kinds of results in the flow of health-related ideas and practices. We chose institutions that were typical of the landscape of healthcare service providers in each context. Because the state dominates the Chinese health sector, we focused on the local medical university and nursing school, the Academy of Social Sciences, and the Center for Disease Control at the city and county levels, as well as a number of nongovernmental organizations. In India the spectrum of healthrelated institutions is broader, and our research included not only elite, government-run educational institutions (the Indian Institute of Management and the Central University of Gujurat), but also smaller private for-profit as well as not-for-profit institutions. Interviewees included men and women at different levels of seniority, from deans and agency directors, to more recently returned junior professors and medical staff. To protect the anonymity of our respondents, our sites are referred to by pseudonyms here.

\section{Migrant destinations and their implications}

Where health professionals went abroad to work and study strongly shaped the ideas and practices they were exposed to about how health should be assessed, maintained, and restored. In India, the vast majority of returnees had studied or worked in North America, Europe, or other developed countries, and mostly in medical schools, tertiary care institutions, or schools of public health. Some of these individuals were sent abroad by their employers to study and gain practical experience. Others went of their own accord in search of better professional opportunities. In most cases, their goal was to train and work at the best institutions, offering the most sophisticated state-of-the-art care or medical research. Only a small number went to learn more communitybased or public health approaches.

In China the range of destinations was broader. Decisions about where to go for further education were guided by a combination of personal networks and funding opportunities that have changed over time. Following the beginning of reform in the late 1970s and early 1980s, most of those who went overseas to study were government-sponsored and had little say over their destination or program. Although many respondents said that they hoped studying abroad would help them contribute more effectively to China's development, which they defined broadly as poverty alleviation, in few cases did they choose programs on the basis of clear knowledge about their content, how they might further their own professional goals, or how what they learned might be relevant to the health challenges of Southwest China. Most respondents applied to particular programs based on the recommendations of their mentors and on the basis of their prestige. Because at this time China was seeking to catch up on research and higher education after the disruptions of the Cultural Revolution, most state-funded researchers went to well-known schools of public health, medical schools, or research universities in North America, Europe, and Australia. This pattern continued as the number of self-funded students grew in the 1980s and thereafter.

The notable exception was individuals who were funded to go overseas by the Ford Foundation International Fellowship Program, which ran from 2001 to 2011. Applicants to this program, which focused on disadvantaged groups including ethnic minorities and women from poor areas of China, were strongly encouraged to consider programs in Southeast Asia, in particular Thailand and the Philippines. A small number also studied health-related topics in the context of broader international development programs which were much more targeted towards problems common to developing countries, and participants generally returned to do fieldwork in China. In India, while most students also went to prestigious public health programs in the global North, a similar exception was the small number of the Future Faculty Members from Health Care For All (HCFA) who completed Masters and PhD programs in the global South or participated in practicums there. These respondents often went to Africa, probably also as a result of previous migration flows and networks.

Despite the similarities in the health-related challenges facing the two countries, no respondents had been involved in exchanges between India and China as part of their medical education, although some subsequently interacted through internationally funded projects such as the Gender and Health Equity Network. In general, most overseas experience also involved working with urban populations; only a few participants worked in rural areas.

\section{Individual, institutional, and societal effects}

We found that international experience had multiple, and sometimes contradictory, impacts on individual, institutional, and societal levels. At the individual level, time abroad led nearly all of our respondents to develop a firm belief in the value of more open and equal interactions and relationships between medical personnel and patients, and between students and teachers. Regardless of where they studied, both Indian and Chinese respondents spoke of coming to realize the importance of involving patients and communities in healthcare decisions, for example, through concepts such as "whole patient care" and "community health." They also said that they had learned a great deal from the methods of teaching and the structuring of interactions between students and teachers. In particular, the emphasis on self-directed learning, classroom participation and practical experience were all aspects of international programs that respondents appreciated, and in many cases hoped to use in their own institutions. They particularly valued being able to challenge their instructors and to engage in meaningful discussions with them, thinking critically and creatively as equal partners responsible for their own learning.

Although these comments were common to both sites, the extent to which respondents were able to apply these ideas on their return varied. In China, the fact that most individuals returned to state-run institutions with quite fixed curricula and professional practices meant that there was relatively little room for introducing innovative practices. Although many respondents talked about attempting to introduce new teaching methods such as case studies, discussion groups, and participatory research into their departments, this was difficult in a context where much of the curriculum was directed toward imparting predetermined content on which students would be tested. Approval processes for new courses are also quite complicated in China. Some respondents did succeed: one professor at a medical school was able to design and teach an 18-hour course on EcoHealth; and others, seeking to create their own space for innovation, began to work full- or part-time in the NGO sector, including one organization established by a group of returnees in the early 1990s specifically to promote participatory, action-oriented research and interdisciplinary exchange on issues related to public health.

In India, the more open institutional environment made it easier 
to introduce new methods of teaching. In fact, some institutions were founded precisely with this goal in mind. Health Care for All (HCFA), for example, was founded in 2006 to introduce a public health perspective to medical care, and to provide additional training to medical professionals employed in the government primary and community health care systems. Many faculty hired to teach these courses have Masters or PhD degrees in public health from programs at leading universities in the United States and the United Kingdom that expose students from around the world to a standard set of research and evaluation methods. The curriculum our respondents taught when they returned replicated many aspects of these courses.

But other influences worked against this commitment to more egalitarian approaches; in particular the content of the programs that respondents attended and their underlying assumptions about the determinants of health and healthcare provision. As a result, despite their good intentions, many of our respondents were in fact exacerbating inequalities at the institutional and societal levels.

What respondents learned overseas was shaped by a combination of their professional specialties and the health problems prevalent in the countries in which they studied. Individuals who studied epidemiology and clinical medicine in North America, Europe, and Australia spoke of having learned primarily technical, research, and management techniques that were new in China and India, or at least in Southwest China and Gujurat. In some cases, they became aware of important health issues they had previously overlooked. For example, several of our respondents in China studied environmental epidemiology and toxicology in Germany, and their experience catalyzed the development of a concentration in this specialty at the local medical school. However, most programs focused on chronic, non-communicable health problems typical of developed countries and used approaches that assumed access to sophisticated medical equipment and trained personnel. Little consideration was given to how these approaches and techniques might be adapted for use in developing country settings, or to the idea that public health might be more effectively enhanced through a more preventive, ecological approach.

The clear exceptions were individuals who went to study in Thailand and the Philippines, or who studied public health in the context of broader development studies programs. They were exposed to very different ideas and experiences, and developed much more holistic understandings of health as determined by broader social, economic, and political trends. Programs at Mahidol University and Chiang Mai University in Thailand, which emphasize strategies for tackling health problems in Southeast Asia and where students conduct lengthy periods of fieldwork back in their home regions, seemed to have provided frameworks and experience more appropriate for health professionals returning to work in Southwest China. Respondents also found that interacting with other students from developing countries and comparing the challenges and opportunities they faced was particularly valuable. One professor wrote a dissertation that directly addressed the problem of translating health-related knowledge by considering the relevance of international experience to the development of China's rural health system.

These examples, however, serve primarily to highlight a more general trend-that most of what our respondents learned while studying abroad did not fit well with the actual health provision and health education needs of the second-tier cities we studied. Although chronic, lifestyle-related diseases like hypertension and diabetes are on the rise, our research sites in China and India both faced much more complex burdens of disease. Furthermore, even in addressing the rise in non-communicable diseases, it is questionable whether reproducing a developed country model that emphasizes high cost curative care over prevention is desirable. "Why not study in Thailand or Sri Lanka, which are more similar to the Indian context?," one professor asked. In China, while nearly all of the respondents supported by the Ford Foundation to attend MA and PhD programs in Thailand and the Philippines said initially they hoped to study in the US and Europe, which they saw as more "advanced," they later realized the programs in Southeast Asia provided them with tools much more useful in the Chinese context.

But these respondents were in a minority. In general, the international knowledge being acquired by the majority of health professionals served the needs of relatively well-off populations and contributed to the trend towards the provision of expensive curative care over preventive medicine. This lack of fit is more pronounced in India due both to the greater need for basic health services and to the greater private sector role in healthcare provision. These dynamics make it easier for returnees to set up largely for-profit private hospitals and medical training institutions. In China, where the public sector still dominates healthcare provision and health education, most returnees work at teaching hospitals or the Ministry of Health and Centers for Disease Control. Although private hospitals are on the rise, the Chinese state will still play the major role in healthcare provision for the foreseeable future.

\section{Integrating local and global knowledge}

The literature on knowledge circulation emphasizes the need for international ideas and practices to mesh with local knowledge if they are to be successfully integrated into local institutions (Acharay, 2004; Rodrik, 2008; Levitt and Merry, 2009). But despite the importance that institutions placed on recruiting returnees, very few processes were in place in either country to enable a systematic, considered absorption and adaption of the global knowledge they bring.

At the same time, different institutions in the two countries were more or less open, and thoughtful about, the introduction of ideas and practices derived from abroad. In many cases there was a clear tension in balancing these with local needs. HCFA, for example, is consciously trying to achieve the right balance between imported practices and local knowledge. According to HCFA's director of research,

"We are creating a global public health that is a mishmash of perspectives gleaned from around the world but is definitely generated in Western powerful institutions. Most of us are part of very elaborate networks, globally, and that influences the world that we live in.... This institution aims to be very progressive, not to be bound by historical baggage, and very Indiacentric.... We don't want to be disconnected from the rest of the world because a lot of good things are happening, we've learned a lot from ideas and developments in public health, in team research and training elsewhere in the world.... We also believe that this should not bias us toward what is important for India, India's public health."

In China there is less support for returnees who wish to adapt and apply overseas ideas and practices to the home context. This is true both of new approaches to thinking about and practicing healthcare and to innovative teaching and learning methods. Although top-tier institutions in Beijing, Shanghai, and other major cities already have highly internationalized programs with participatory teaching methods, this is not yet true in less well-resourced regions. For example, course content at the Southwest China Medical University is largely dictated from above, and the need to prepare students for examinations severely restricts professors' abilities to introduce new material or teaching methods. Out of 1589 staff, more than 300 have spent at least three months abroad. 
Yet despite the requirement for overseas study and the focus on recruiting returnees, many of them complained that there is no attempt to consciously assess and mobilize the knowledge that they acquire abroad. In 2010, the University formed a Returnee Association that organizes social events and lectures, and which could potentially act as a platform for the integration of international experience, but it does not in fact serve this purpose. Some respondents indicated that support for international exchange has actually declined in recent years because of the retirement of the dean, a returnee, who had been supportive of maintaining international networks. That so much depends on the leadership of a particular individual also speaks to the lack of institutionalized mechanisms for absorbing and adapting global knowledge. In general, consideration of how to adapt international knowledge and practices seemed to occur only in individual cases or through the mediation of organizations like the NGO returnee network mentioned above.

The fact that most returnees studied in North America and Europe also meant that few had the opportunity for comparison or mutual learning about other countries facing similar problems. The lack of mechanisms for exchange between Chinese and Indians is particularly glaring given the similarity in the health challenges they face. With a few exceptions, such as the Gender and Health Equity Network and the International Development Research Centre's Ecosystems and Human Health Program, most collaborative efforts involve Western institutions reaching out separately to China and India, rather than lateral connections between the two. This is unfortunate because Chinese and Indian health professionals could learn a great deal from each other. Furthermore, China and India have their own indigenous, holistic approaches towards the prevention and management of chronic diseases from which all countries can learn. This asset is recognized in principle (WHO, 2013) but not emphasized in international exchanges that are generally premised on the across-the-board superiority of Western medical traditions.

So far our discussion has focused on similarities among our respondents, but they of course also differed in many respects. In particular, the point in their careers at which individuals went overseas and the length of time they stayed had implications for their integration into local institutions on their return. In particular, individuals who went abroad without work experience and who "grew up" professionally overseas come back accustomed to different ways of doing things, organized around different social hierarchies, rules, and values than those in place back home. On return, they first have to learn the rules of the local workplace and build social networks from scratch. In Gujurat, while some colleagues admired our respondents for their contacts abroad, others resented them for having "jumped ship" while they remained behind in India. Too much talk about "what we did in England or Canada" sometimes backfired, especially if it was not accompanied by a healthy dose of respect and praise for Gujarati ways and accomplishments (Levitt and Rajaram, 2013).

When Chinese respondents went abroad in the arc of their careers also influenced their ability to incorporate local and international norms and approaches into their research, teaching, and administrative roles. Those who trained and worked in China before leaving could deploy a range of tactics in their efforts to bring about change, while those who received their professional education largely in developed countries often found themselves like fish out of water and went through fairly lengthy adjustment periods. This situation caused tension in some institutions, with factional divisions developing between returnees and those who have not studied abroad.

The use of English as a medium for learning and teaching about international ideas and practices also created hierarchies between people able and not able to use the language professionally. There was more awareness of this in India, where the issue of English as a medium of education in relation to both Hindi and local languages has been an issue of debate since Independence. Similar issues have arisen as more Chinese study abroad, and many elite universities have begun to introduce English language classes, but the tradeoffs between access to international knowledge and inclusiveness that these entail are not always directly considered. For example, the nursing school in the city we studied had been sending nurses to Southeast Asia for training for some years and planned to reproduce these courses back in China using English language materials. Aside from questions about the cultural appropriateness of the content, this meant that students had to spend a considerable amount of time learning English, a difficult task for many of them, when all their future patients would be Chinese.

\section{Challenges to participation in the global production of knowledge}

The majority of this article has focused on the role of returnees in the practice of healthcare and in health education in their countries of origin. But in studying overseas, many of our respondents-especially those working in universities-also became members of international networks of researchers. Upon their return to India and China, they wanted to continue to participate in the production of internationally recognized research on healthrelated issues. Although space prevents an extended analysis, in this last section we discuss briefly a few of the challenges they faced in doing so, which is interesting particularly in the context of China's growing presence in international health and development efforts.

The obstacles to ongoing participation in international research networks fell into two broad categories: the availability of data and ethical considerations. In terms of data, the major challenges are that comprehensive disease surveillance systems are fairly recent in both countries and, especially in India, and the quality of data they generate is somewhat unreliable. In China there is the added problem that a lot of data are not publicly available. In terms of professional ethics, human subjects requirements are also a challenge; some respondents mentioned that the concept of informed consent can be hard to put into practice when respondents have limited education or when disclosure of information is not permitted by the state. Other challenges respondents mentioned were that state-funded research in China has generally, and justifiably, had an applied focus that is seen as less prestigious in international publishing; access to international journals is also limited, as second- and third-tier universities do not pay for access to databases; and although returnees have better English language skills than those who do not go abroad, many of them said that keeping up with large and wide-ranging literature remains a struggle. These factors prevent many returnees from continuing lines of research that they began abroad. For example, one respondent in China estimated that only 30\% of returnees to Southwest China Medical University had managed to pursue serious research agendas on their return.

\section{Conclusions and implications}

Although many skilled migrants are motivated primarily by a desire to pursue their own career goals and increase their earning capacities, a significant number of medical professionals go overseas to learn ideas and skills that they believe will contribute to their country's development. Governments and private foundations also support overseas education based on the assumption that it benefits not just individuals but also the institutions in which 
they work and society as a whole. Yet as Kapur's (2010) work on the impact of returnees more generally suggests, the presence of return migrants and individuals with strong transnational connections can have complex and contradictory implications for institutional development and power relations in the sending society. We found this to be the case in the healthcare field.

On the individual level, participants in our study benefited enormously from their time overseas, and not only in terms of practical skills. Many developed a new commitment towards increased openness and equality in interactions between doctors and patients and teachers and students. However, although in many cases these individuals have actively tried to apply these principles in their medical practice, research, and teaching, they remain marginal to the dominant trends in health service provision and education. In India some institutions were actively attempting to apply international methods of teaching and practice, but at least in the institutions we studied in China there were no embedded mechanisms to support conscious processes of distilling and adapting international knowledge to local contexts, and these processes depended on individual sponsors.

At the same time, particularly in India, international experience exacerbated the existing mismatch between local health needs and the institutions and programs in place to address them. It also exacerbated inequality within and between health providers, and in the schools where health professionals are educated. In general, returning students and professionals in both countries brought back knowledge and skills more suited to top-tier hospitals and medical schools than to the second- or third-tier institutions where they worked. To the extent that there is a fit between what they learned and the health needs of the communities to which they return, it centers on the needs of the wealthy and the emerging middle classes and is less suited to addressing those of the rural and urban poor. Most of the study programs Indian and Chinese students attend emphasize biomedical, curative, and institutionally based approaches that reproduce the high-cost, interventionist practices of the developed countries. There is little parallel training in integrated approaches to public health that emphasize prevention and lower-cost, culturally grounded treatments. Flows of knowledge are also dominated by transfers from developed to developing countries, and do little to foster knowledge-sharing among health professionals in developing countries or two-way exchanges between countries in the global North and global South.

As the literatures on policy learning, global knowledge circulation, and capacity building show, there are many ways in which the international experience of professional migrants might influence the ways in which they pursue their careers and contribute to policy and institutional development. This project was limited in scope and could not explore all these dimensions. However, our research showed that we certainly should not take for granted either the relevance of developed country experience in the health sector or the smooth transfer of what is learned. If international educational programs are to improve equitable access to appropriate and affordable healthcare and more effective disease prevention, we need to think harder about the implications of different educational pathways (including country of destination, type of program, and specific content) and their relationship to needs in the sending place.

\section{Acknowledgments}

This research was supported by the MacArthur Foundation (Grant No. 92477-0).

\section{References}

Alcorn, T., Bao, B., 2011. China progresses with health reform but challenges remain. Lancet 377 (9777), 1557-1558.

Acharay, A., 2004. How ideas spread: whose norms matter? Norm localization and institutional change in Asian reigonalism. Int. Organ. 58 (2), 239-275.

Beaglehole, R., Bonita, R., Horton, R., Adams, C., Alleyne, G., Asaria, P., Baugh, V., Bekedam, H., Billo, N., Casswell, S., Cecchini, M., Colagiuri, R., Colagiuri, S. Collins, T., Ebrahim, S., Engelgau, M., Galea, G., Gaziano, T., Geneau, R., Haines, A., Hospedales, J., Jha, P., Keeling, A., Leeder, S., Lincoln, P., McKee, M., Mackay, J., Magnusson, R., Moodie, R., Mwatsama, M., Nishtar, S., Norrving, B., Patterson, D., Piot, P., Ralston, J., Rani, M., Reddy, K.S., Sassi, F., Sheron, N., Stuckler, D., Suh, I., Torode, J., Varghese, C., Watt, J., 2011. Priority actions for the non-communicable disease crisis. Lancet 377 (9775), 1438-1447.

Bennett, C., 1991. How states utilize foreign evidence. J. Public Policy 11 (01), 31-54.

Bloom, G., Standing, H., 2008. Future health systems: why future? why now? Soc. Sci. Med. 66 (10), 2067-2075.

Castles, S., Delgado Wise, R. (Eds.), 2008. Migration and Development: Perspectives from the South. International Organization on Migration, Geneva.

Corvalán, C., Kjellström, T., Smith, K., 1999. Health, environment and sustainable development: identifying links and indicators to promote action. Epidemiology 10 (5), 656-660.

Dawes, S., Mohamed, G., Barke, B., 2011. Knowledge and information sharing in transnational knowledge networks: a contextual perspective. In: Proceedings of the 44th Hawaii International Conference on System Sciences.

De Haas, H., 2008. Migration and Development: a Theoretical Perspective. International Migration Institute Working Paper No 9. James Martin 21st Century School, University of Oxford, Oxford.

Dolowitz, D., Marsh, D., 1996. Who learns what from whom: a review of the policy transfer literature. Polit. Stud. 44 (2), 343-357.

Dolowitz, D., Marsh, D., 2000. Learning from abroad: the role of policy transfer in contemporary policy-making. Governance 13 (1), 5-23.

Duan, Y., 2010. Identifying key factors affecting transnational knowledge transfer. Inf. Manag. 47 (7), 356-363.

Dummer, T., Cook, I., 2008. Health in China and India: a cross-country comparison in a context of rapid globalisation. Soc. Sci. Med. 67 (4), 590-605.

Eckstein, S., Najam, A., 2013. How Immigrants Impact Their Homelands. Duke University Press, Durham.

Fang, P., Dong, S., Xiao, J., Liu, C., Feng, X., Wang, Y., 2010. Regional inequality in health and its determinants: evidence from China. Health Policy 94 (1), 14-25.

Filc, D., 2004. The medical text: between biomedicine and hegemony. Soc. Sci. Med. 59 (6), 1275-1285.

Freeman, C., Boynton, X., 2011. Implementing Healthcare Reform Policies in China: Challenges and Opportunities. Center for Strategic and International Studies, Washington, D.C. Retrieved from: https://csis.org/publication/implementinghealth-care-reform-policies-china.

Gong, P., Liang, S., Carlton, E., Jiang, Q., Wu, J., Wang, L., Remais, J., 2012. Urbanisation and health in China. Lancet 379 (9818), 843-852.

Government of India, Planning Commission, 2011. Report of Working Group on Disease Burden for 12th Plan. Non-Communicable Diseases Working Group $3(2)$.

Government of India, Planning Commission, 2012. Strategy Challenges. Retrieved from. http://12thplan.gov.in/displayforum_list.php.

Holdaway, J., 2013. Environment and health research in China: the state of the field. China Q. 214, 1-28.

Holdaway, J., Marshall, F., 2010. Integrating environment, health and development in the transition to urbanization and industrialization: applying the ecosystems services-poverty alleviation (ESPA) framework to China and India. Paper Presented at the Sino-India Workshop on Ecosystems Services and Poverty Alleviation, Beijing.

Husain, L., 2012. Implementing and Innovating: Local Governments in the Development of China's New Cooperative Medical Scheme (PhD thesis). University of Leeds, School of Modern Languages and Cultures, Leeds.

Jons, H., 2011. Transnational academic mobility and gender. Glob. Soc. Educ. 9 (2), $183-209$.

Jons, H., 2009. Brain circulation and transnational knowledge networks: studying long-term effects of academic mobility to Germany, 1954-2000. Glob. Netw. 9 (3), 315-338.

Kangasniemi, M., Winters, L., Commander, S., 2007. Is the medical brain drain beneficial? Evidence from overseas doctors in the UK. Soc. Sci. Med. 65 (5), 915-923.

Kapur, D., 2010. Diaspora, Development, and Democracy: the Domestic Impact of International Migration from India. Princeton University Press, Princeton.

Kapur, D., McHale, J., 2005. Give us Your Best and Brightest: the Global Hunt for Talent and its Impact on the Developing World. Center for Global Development, Washington, D.C.

Lafleur, J.M., 2013. Transnational Politics and the State. The External Voting Rights of Diasporas. Routledge, New York.

Lennard, C., 2012. Euromonitor International. Retrieved from: http://blog. euromonitor.com/2012/08/india-lagging-far-behind-china-in-female-literacyand-employment-rates.html.

Levitt, P., 1998. Social remittances: migration driven, local-level forms of cultural diffusion. Int. Migr. Rev. 4, 926-948.

Levitt, P., Lamba-Nieves, D., 2011. Social remittances revisited. J. Ethn. Migr. Stud. 37 
(1), $1-22$.

Levitt, P., Merry, S., 2009. Vernacularization on the ground: local uses of global women's rights in Peru, China, India and the United States. Glob. Netw. 9 (4), $441-461$.

Levitt, P., Rajaram, N., 2013. Moving toward reform? Mobility, health, and development in the context of neoliberalism. Migr. Stud. 1 (3), 338-362.

Lu, L., Yuan, X., Cheng, C., 2009. History, current state and challenges of infectious diseases in Yunnan (in Chinese). J. Kunming Med. Univ. 8, 17-20.

Luo, K., Guo, F. Huang, P., 2003. China: government policies and emerging trends of reversal of the brain drain. In: Iredale, R., Guo, F., Rozario, S. (Eds.), Return Migration in the Asia Pacific. Edward Elgar, Northampton.

Mannan, H., Amin, M., MacLachlan, M., 2012. Non-communicable disease priority actions and social inclusion. Lancet 379 (9812), 17-18.

Mark, A., Jones, M., 2013. Thinking through health capacity development in fragile states. Int. J. Health Plan. Manag. 28 (3), 269-289.

Marquez, P., Langenbrunner, J., Wang, S., 2011. Toward a Healthy and Harmonious Life in China: Stemming the Rising Tide of Non-communicable Diseases. The World Bank, pp. 1-48 (63426) Retrieved from: http://documents.worldbank. org/curated/en/2011/07/14639951/toward-healthy-harmonious-life-chinastemming-rising-tide-non-communicable-diseases.

Mazzucato, V., 2011. Reverse remittances in the migration-development nexus: two-way flows between Ghana and the Netherlands. Popul. Space Place 17.

Mullan, F., 2005. The metrics of the physician brain drain. N. Engl. J. Med. 353 (17), $1810-1818$.

Okeke, E., 2013. Brain drain: do economic conditions "push" doctors out of developing countries? Soc. Sci. Med. 98, 169-178.

Ong, A., 2011. Introduction: Worlding cities, or the art of being global. In: Roy, A, Aiwa, O. (Eds.), Worlding Cities: Asian Experiments and the Art of Being Global. Wiley-Blackwell, Oxford.

Parker, S., Khatri, R., Cook, I., Pant, B., 2014. Theorizing aging in Nepal: beyond the biomedical model. Can. J. Sociol. 39 (2), 231-254.

Peck, J., 2011. Geographics of policy: from transfer-diffusion to mobility-mutation. Prog. Hum. Geogr. 35 (6), 773-797.

Pritchett, L., Woolcock, M., Andrews, M., 2012. Looking Like a State: Techniques of Persistent Failure in State Capability for Implementation. WIDER Working Paper 63. Retrieved from: http://handle.net/10419/80903.

Robertson, D., 1991. Political conflict and lesson-drawing. J. Public Policy 11 (01), 55-78.

Rodrik, D., 2008. Second-best Institutions. National Bureau of Economic Research Working Paper 14050. Retrieved from: http://www.nber.org/papers/w14050.

Rose, R., 1991. What is lesson-drawing? J. Public Policy 11 (01), 3-30.

Saxenian, A., 2006. The New Argonauts: Regional Advantage in a Global Economy. Harvard University Press, Cambridge, Massachusetts.

Sen, A., 2011. Learning from others. Lancet 377 (9761), 200-201.

Sherr, K., Mussa, A., Chilundo, B., Gimbel, S., Pfeiffer, J., Hagopian, A., Gloyd, S., 2012. Brain drain and health workforce distortions in Mozambique. PLoS One 7 (4).

Smith, K., Ezzati, M., 2005. How environmental health risks change with development: the epidemiologic and environmental risk transitions revisited Annu. Rev. Environ. Resour. 30 (1), 291-333.

Taylor, A., Hwenda, L., Larsen, B., Daulaire, N., 2011. Stemming the brain drain-A WHO global code of practice on international recruitment of health personnel N. Engl. J. Med. 365 (25), 2348-2351.

The World Bank, 2012. Data, Countries and Economies: China. Retrieved from: http://data.worldbank.org/country/china.

Times of India, July 12 2010. 8 Indian States Have More Poor than 26 Poorest African Nations. Retrieved from: http://articles.timesofindia.indiatimes.com/2010-0712/india/28276383_1_measure-ophi-multidimensional-poverty-index (accessed 03.10.12.).

Vital Statistics Division, Commissionerate of Health, Medical Services, Medical Education and Research, Gandhinagar, Gujarat State, 2012. Health Statistics: Gujarat, 2010-2011. Retrieved from: http://www.gujhealth.gov.in/images/pdf HEALTH_STATISTICS_2010-11.pdf (accessed 03.10.12.).

World Health Organization/UNICEF, 2012. Progress on Drinking Water and Sanitation: 2012 Update. Retrieved from: http://www.unicef.org/media/files/ JMPreport2012.pdf.

World Health Organization, 2013. WHO Traditional Medicine Strategy: 2014-2023. Retrieved from: http://www.who.int/medicines/publications/traditional/trm strategy14_23/en/ (accessed 10.12.14.).

World Health Organization (WHO), 2008. Closing the Gap in a Generation: Health Equity Through Action on the Social Determinants of Health. Final report of the Commission on Social Determinants of Health. WHO, Geneva.

World Health Organization (WHO), 2005. Ecosystems and Human Wellbeing Health Synthesis. WHO, Geneva.

World Health Organization (WHO), September 1978. Declaration from the International Conference on Primary Health Care. Alma-Ata.

Wilkinson, R., Marmot, M., 2003. Social Determinants of Health: The Solid Facts. WHO, Geneva.

Xiang, B., 2003. Emigration from China: a sending country perspective. Int. Migr. 41 (3), 21-48.

Xiang, B., 2006. Promoting knowledge exchange through diaspora networks: the case of the People's Republic of China. In: Wescott, C., Brinkerhoff, J. (Eds.), Converting Migration Drains into Gains: Harnessing the Resources of Overseas Professionals. Asian Development Bank, Manila, pp. 33-72.

Yang, G., Wang, Y., Zeng, Y., Gao, G.F., Liang, X., Zhou, M., Wan, X., Yu, S., Jiang, Y. Naghavi, M., Vos, T., Wang, H., Lopez, A.D., Murray, C.J., 2013. Rapid health transition in China, 1990-2010: findings from the global burden of disease study 2010. Lancet 381 (9882), 1987-2015.

(in Chinese), Zhongguo ditu chubanshe, Beijing. In: Yang G., Zhuang. D. (Eds.), 2013 Atlas of the Water Environment and Digestive Cancer Mortality in the Hua River Basin. Sino-Maps Press, Beijing.

Zhang, J., Mauzerall, D., Zhu, T., Liang, S., Ezzati, M., Remais, J., 2010. Environmenta health in China: progress towards clean air and safe water. Lancet 375 (9720), $1110-1119$ 